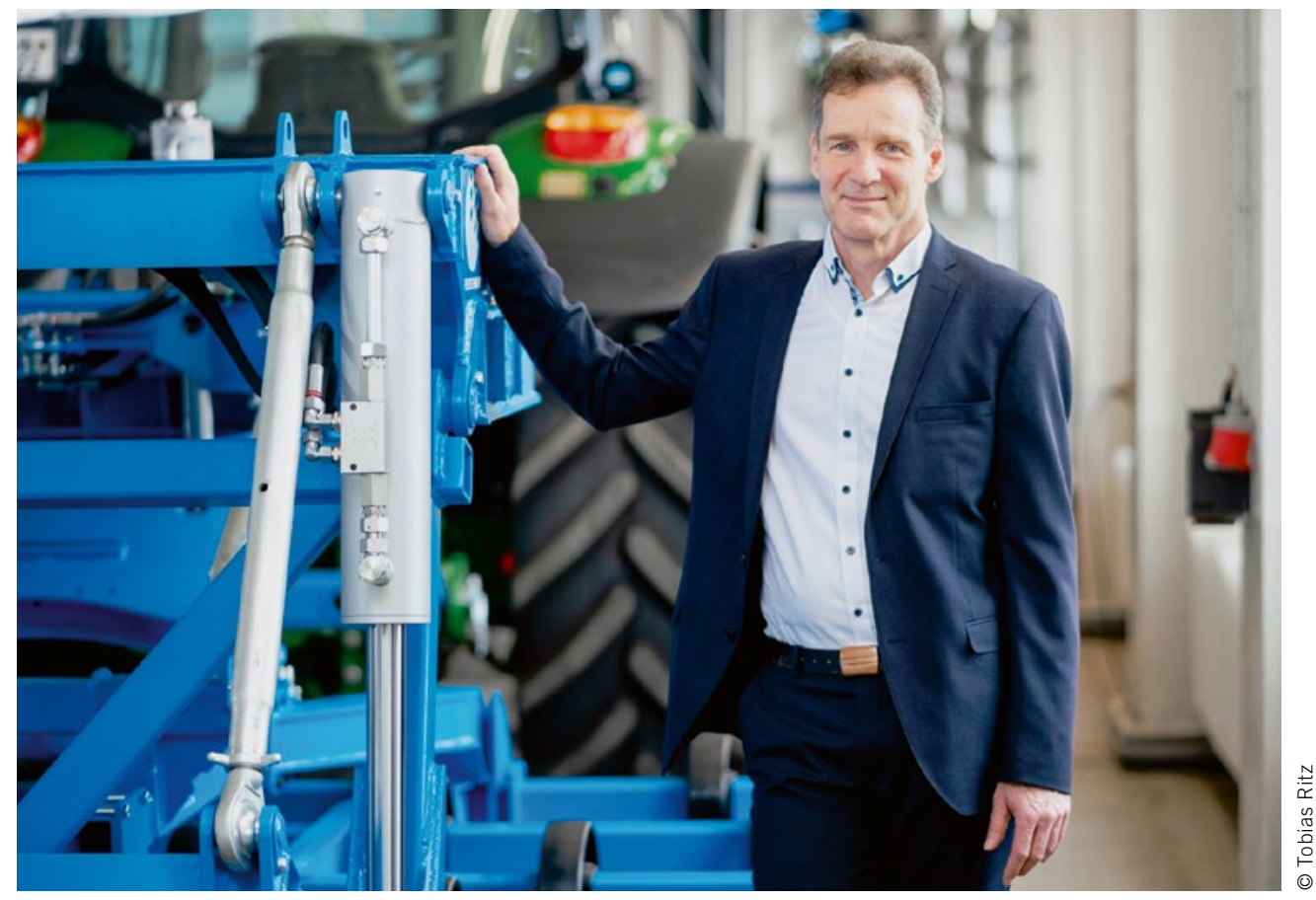

Prof. Dr.-Ing. habil. Thomas Herlitzius Lehrstuhlleiter Agrarsystemtechnik sowie Direktor des Instituts für Naturstofftechnik der Technischen Universität Dresden

\title{
Autonome mobile Maschinen in der Landtechnik - Wie geht es weiter?
}

Landwirtschaft 4.0 ist die Zukunftsvision, in der intelligente Systeme vernetzt sind, miteinander kommunizieren und kooperieren, sodass eine hochautomatisierte Produktion möglich wird. Es gibt bereits eine Vielzahl an intelligenten und digitalen Helfern, und es finden sich nun auch vermehrt Ideen von kleineren Maschinen, die selbstständig und fahrerlos agieren können. Das wäre ein Paradigmenwechsel und fundamentaler Wandel von Landmaschinentechnik. Der Trend zu immer größeren Maschinen wird abgelöst: Autonom operierende, flexibel konfigurierbare, aufgabengerecht skalierbare Gerätesysteme mit verteilten elektrischen Antrieben halten beginnend in Westeuropa schrittweise Einzug in den Markt. Der Bediener wird Teil des Systems sein, aber nicht jede einzelne Maschine wird tatsächlich auch einen Bediener haben. Der Landwirt ist der Schwarmführer, der das System überwacht, organisiert und konfiguriert. Vor der Vollautomatisierungslösung kommt der kollaborative Ansatz, bei dem der Landwirt kontinuierlich mit dem System interagiert und schwierige oder nicht wirtschaftlich zu automatisierende Aufgaben selbst übernehmen kann.

Oft wird der Zeithorizont 2030 genannt, aber selbst wenn eine knappe Hälfte von befragten Landwirten sich das bis dahin vorstellen kann, wird das in der Breite nicht stattfinden können, weil wir insgesamt in der Entwicklung noch nicht soweit sind. In einzelnen Nischen werden wir allerdings durchaus solche Entwicklungen sehen: im Gartenbau, im Obstbau, in kleineren Betrieben, in Biobetrieben, eben dort wo höhere Wertschöpfung betrieben werden kann und Arbeitskräfte fehlen. Es wird eine lange Übergangsphase geben, und nicht alle Maschinen, wie wir sie heute kennen, werden verschwinden. Vielmehr wird eine neue Welt von kleineren intelligenten Maschinen hinzu kommen, die in der Lage ist, mit der alten Welt zu kooperieren und zu interagieren.

Der Landwirt ist und bleibt in seinen Kompetenzen in der Pflanzenproduktion nicht ersetzbar. Er wird auch kein IT- und Smart-Farming-Spezialist werden müssen. Die Industrie überfordert den Landwirt noch mit Technikinseln und Applikationen, die er nicht verbunden bekommt. Das mühselige Hinund Hertragen von Daten und Inkompatibilität kompensiert oft den erzielbaren Nutzen. Zukünftig wird der Landwirt die einfach zu bedienenden Anwendungen und Tools verschiedener Dienstleister richtig einsetzen, koordinieren und in seinem Betrieb so miteinander verknüpfen können, dass der Produktionsprozess profitabel, in hoher Qualität, transparent und nachhaltig stattfindet. So wie der Landwirt sich heute seinen Maschinenpark zusammenstellt, wird er sich zukünftig sein Dienstleistungsportfolio zusammenstellen. 